\title{
Student Perceptions of Learner-Centered Teaching
}

\author{
DeDe Wohlfarth, PsyD \\ Associate Professor, Department of Psychology \\ Spalding University \\ Daniel Sheras, MA \\ Jessica L. Bennett, MA \\ Bethany Simon, BA \\ Jody $\mathrm{H}$. Pimentel, MS \\ Laura E. Gabel, MA \\ Graduate Students, Department of Psychology \\ Spalding University
}

The learner-centered paradigm departs from traditional teaching models by focusing on students more than teachers and learning more than teaching. Thus, classes are more egalitarian; they emphasize critical thinking, active learning, and real-world assignments. Graduate students in learner-centered classrooms were surveyed about perceptions of their experiences in relation to the key dimensions of the learner-centered paradigm and noted that the approach contributed to their feeling respected as learners, developed their critical thinking skills, and encouraged their self-directedness. Based on these findings, post-secondary instructors are encouraged to experiment with learning-centered approaches to further explore this promising model.

"Education is not filling a bucket but lighting a fire."

-William Butler

\section{Introduction: Context for Learner-Centered Teaching}

Learner-centered teaching (Bilimoria \& Wheeler, 1995; Weimer, 2002) represents a paradigm shift from traditional teaching methods by focusing on how students learn instead of how teachers teach. Thus, the model's conceptual underpinning is rooted in learning, challenging us to ask the rarely heard question, "How can I improve my students' learning?" instead of the often asked "How can I improve my teaching?" (Weimer, 2002). Weimer outlines the key premises of learner-centered teaching as:

1) Assume that students are capable learners who will blossom as power shifts to a more egalitarian classroom.

2) Use content not as a collection of isolated facts, but as a way for students to critically think about the big questions in the field.

3) Change the role of teacher from sole authoritarian to fellow traveler in search of knowledge.

4) Return the responsibility for learning to the students, so that they can understand their learning strengths and weaknesses and feel self-directed in their knowledge quest.

5) Utilize assessment measures not just to assign grades, but as our most effective tools to promote learning.

The result of this paradigm shift is that teachers become co-learners with students, thus blurring the categorical distinction between these two groups. The broad learner-centered paradigm encapsulates our current understanding of the "best practices" in teaching, including an emphasis on active learning (McKeachie \& Svinicki, 2006; Thompson, Licklider, \& Jungst, 2003), problem-based learning (Blumberg, 2007) and, more generally, a thoughtful understanding of what the best teachers actually do in their classrooms (Bain, 2004). Of particular relevance to the 
present discussion, Bain notes that excellent teachers foster critical thinking, have a strong trust in students, and are life-long learners themselves.

In response to the learner-centered movement, we have exchanged copious lecture notes and multi-bullet point slides for a more active, engaging, collaborative style of teaching. Perhaps we have recognized that our technology, and our focus on content over thinking, has eroded much of what appealed to us as teachers in the first place. That is, we became teachers to make a difference in students' lives, and as a socially sanctioned way to shape the values, questions, and thinking of the next generation (Palmer, 1998). Learner-centered teaching involves connecting with knowledge and students at the same time. We intuitively recognize those rare teaching moments when great things are happening in our classroom because we are learning and thinking with our students. Furthermore, when students become lifelong

Learner-centered teaching involves connecting with knowledge and students at the same time.

learners by developing their critical thinking skills and self-management abilities, they are more likely to have success in the post-college "real world" than if they were merely phenomenal multiple-choice test takers.

Indeed, adopting a learner-centered perspective, with its emphasis on trusting students and loosening our grip on content-driven lectures, is challenging. It requires students and professors alike to embrace its inherent contradictions and paradoxes, including being both a facilitator and an evaluator and being both a learner and a teacher (Robertson, 2005). At times, learner-centered teaching demands us to join the students on their learning journey while simultaneously requiring us to grade their work and evaluate their performance. The degree to which we can live with these tensions is affected not only by our teaching orientation, but also where we are in our own teaching/learning journey and how well we orient students to our new paradigm (Daley, 2003; Mezeske, 2004). As Ramsey and Fitzgibbons (2005) thoughtfully suggest, learner-centered teaching requires us to move along a continuum beyond "doing something to students" (teaching) to "doing something with students" (teaching and learning) to "being with students" (learning). Even more challenging is moving seamlessly back and forth along this continuum within single class periods, intuitively recognizing what learners need from us in the moment.

Although the learner-centered paradigm has become the new buzzword in the field, empirical support is needed to move the paradigm from a passing trend to a conceptual pillar of scholarship of teaching and learning. Several researchers have explored learner-centered concepts with promising early results. For example, Wells and Jones (2005) examined how teaching informational systems development to students was improved by using a more collaborative, mentoring style of teaching instead of a traditional lecture-based style. They utilized small work groups, personal work portfolios, and student-driven classroom experiences, and reported higher grades among students in the more collaborative classrooms. They also suggest that students learned less measurable but still important skills, such as the ability to work collaboratively and take responsibility for their learning.

Additional support for a learner-centered paradigm comes from Steckol (2007), who assessed how using formative assessment, a component of learnercentered teaching, enhanced student learning. The formative assessment tools utilized included one-minute papers to summarize class material and studentgenerated quizzes. Steckol noted that students in the learning-centered section of the class scored significantly better on the final exam than those in the control group.

Despite promising early findings, empirical support for learning-centered models is in its infancy. Data regarding its usefulness, relevance, and effect on student learning is minimal. A key perspective in understanding the impact of a learner-centered model is through the eyes of students. The learner-centered model focuses on student learning instead of instructor teaching; furthermore, the model 
shifts the balance of power in the classroom to the students. Thus, collecting data from a student perspective is consistent with a learner-centered philosophy, in which students do something instead of having something done to them. The goal of this paper is to increase understanding of learner-centered teaching through a student perspective and add to the body of knowledge so that teachers can better implement this model.

\section{Methods}

Subjects in the current study $(n=21)$ were enrolled in a graduate psychology program at a small liberal arts school in the southeastern United States. The learner-centered classes were taught by one professor but spanned two courses during the 2007-2008 academic year. The courses included an introduction to counseling course ( $1^{\text {st }}$ year graduate students) and a child psychopathology course (primarily $3^{\text {rd }}$ year graduate students). The students in both classes were told that their courses would be taught in a learner-centered style, and this term was explained to them, including describing Weimer's five tenets outlined in this text.

Although learner-centered ideals focus on less-quantifiable concepts of relationships and trust, the following adjustments were also made to the course design to reflect a learner-centered philosophy:

- Classroom activities focused less on prepared lectures and more on student-driven questions and discussion about the reading. Several classes reflected problem-based learning, in that a complex clinical case from one student was the basis for the class discussion. Thus, a "typical" class period might have included an experiential group activity related to the topic; processing of this activity; each student sharing the topic s/he would most like to discuss in relation to the reading; the professor and students jointly deciding how to focus the group discussion from this list of possibilities; and mini-lecturettes from the professor punctuating the discussion. At the end of class, students were asked to summarize key ideas and the relevance of their learning today to their work and lives. Alternatively, an entire classroom period might have been spent struggling with a studentgenerated clinical case, discussing the diagnostic, clinical, and ethical implications of course of treatment.

- Multiple-choice quizzes, which primarily tapped students' memorization skills, were replaced with weekly homework assignments, in which students were asked to apply, integrate, or evaluate the assigned reading. These homework assignments might include integrating ideas from this class with another class; applying key ideas to an actual clinical case; or doing related research by reading and summarizing a related article to the homework.

- All professors' notes were available to students via Blackboard prior to classes. Furthermore, students were also provided with the quizzes they would have taken were they not in a learner-centered class.

- $\quad$ Students determined the content of their research papers and were invited to turn in as many drafts of their papers as they desired, receiving formative, but not evaluative, feedback on each draft.

- $\quad$ Students chose their own assignments from a possible portfolio of options. They were also encouraged to develop their own assignments to replace instructor suggestions.

- Students chose their own due dates for assignments, within certain parameters to allow for thoughtful feedback from the instructor.

- Students were asked to write an end-of-semester self-assessment, focusing on their learning strengths/weaknesses, their assessment of the type and depth of learning in the class, and what they believed their final grade should be. This paper demanded a high level of student reflective thinking.

InSight: A Journal of Scholarly Teaching 
At the end of the semester, data was collected through anonymous supplemental student course evaluations that were based on the work of Brookfield (1995). This evaluation form asked students when they felt most engaged/disengaged in the class, what hindered/helped their learning; their perceptions of the instructor's strengths and weaknesses; and the most important skills, attitudes, and concepts they learned. An additional evaluation form was created to assess the five tenets of learner-centered classrooms, as described by Weimer (2002). This form asked students to complete two Likert scales regarding 1) the extent to which each of the five tenets occurred (on a scale of 1-5) and 2) how important this change was to their learning (on a scale of 1-5). They also had the opportunity to comment about their perceptions of the class, including how (or if) the learner-centered components contributed to their learning, and strengths and challenges of the paradigm.

\section{Results and Discussion}

In examining the first of Weimer's tenets, that power should be returned to students as they are capable learners who will blossom in an egalitarian classroom, the response from students on the supplemental course evaluations was unanimously positive. In terms of students' perceptions of the extent to which the power of the classroom was returned to them, $71.4 \%$ of students noted that this occurred "very" often (" 4 " on Likert scale) and $86 \%$ of students noted that this shift in the balance of power was either "very" or "unbelievably" important to their learning. Qualitative data further supported that students perceived that they were being respected as fellow co-learners in the search for knowledge, as epitomized by the following quote:

- "I have truly enjoyed this class, and the way it was designed as a learner-centered experience. I feel that it was the first time I was treated as a competent and intelligent person who could be trusted with her learning experience."

In understanding the implications of these findings, it seems that students can perceive whether professors inherently trust them, and that they predominately respond to this trust in a positive way.

Weimer's second tenet of learner-centered classrooms is that content is used as a vehicle to promote critical thinking about conceptual questions underlying the field, instead of as isolated facts to be memorized. Interestingly, $100 \%$ of students responding noted that this focus on deeper critical thinking skills, such as integration, application, and evaluation, instead of an emphasis on memorization, did occur. All students responding (100\%) noted that this shift was "very" or "unbelievably" important to their learning. Again, students were markedly positive in their responses:

- $\quad$ "Generally, I believe the learner-centered style of teaching is more helpful to me than traditional lecture-style instruction. I believe that I learn best when there is some, but not an overwhelming amount, of structure. In lecture-style classrooms, I absorb some information and I may answer or may not ask a question, but the most important and useful learning comes from being pushed to critically think about the information. This simply does not occur in lecture focused classrooms."

- $\quad$ "I learn best when I can find personal significance in the material I am studying. In other words, I need to view information not just as a bunch of facts, but also as whole concepts. This class, for the most part, highly stimulated my learning style. For me, class discussions were helpful because it helped me synthesize information and gave relevance to the topics." 
These findings imply that students are not only capable of deeper levels of critical thinking, but understand when such thinking is happening as compared to lower level thinking skills such as memorization. No students surveyed were frustrated by a loss of content covered, despite professors often expressing concerns about reducing the amount of content covered as one of the stumbling blocks to adopting a learner-centered paradigm (Weimer, 2002).

Regarding Weimer's third tenet, that a more egalitarian classroom is established and that professors are seen as fellow travelers on a learning journey, working alongside of students instead of delivering nuggets of knowledge from the academic mountaintop, $97.9 \%$ of students felt that an egalitarian classroom had developed and a similar percentage $(92.5 \%)$ felt that this shift was critical to their learning.

- "I really appreciate that from the first moment of class, and throughout the entire semester, you set up a comfortable learning environment. This makes such a huge difference in a class!"

- $\quad$ "This class has been quite a departure from the teaching style that I have had in the past...and I thoroughly enjoyed it. I like the fact that we were able...to say what we wanted without the fear of being terribly wrong or shunned by the professor."

- $\quad$ "Your comments on my papers made me feel like each week that you and I had our own personal discussion on the topic."

However, some remnants of the older teaching-centered paradigm remain for students, as noted by the following comment:

- $\quad$ "There were a few times when my views on things differed than yours. This was probably the only time that I felt nervous about talking. I guess, even in this round-table like classroom setting, I still view you as the head."

This comment likely reflects the difficulty some students have in adjusting to a more egalitarian classroom, even when they are primed for such a change and encouraged throughout the semester to find their own voices and challenge the professor. The optimum behavior in a learner-centered classroom is, in many ways, a stark contrast to much of the behavior encouraged by traditional classrooms, where students are passive note takers, unquestioning receivers of knowledge from an expert. It seems that students are hungry for the changes brought about by learner-centered teaching, but that adjusting to them can be somewhat difficult and create some anxiety. In general, however, students are able

The optimum behavior in a learner-centered classroom is, in many ways, a stark contrast to much of the behavior encouraged by traditional classrooms, where students are passive note takers, unquestioning receivers of knowledge from an expert.

to perceive and articulate what an egalitarian classroom looks like, perhaps from the very first class session.

In learner-centered classrooms, as Weimer notes in her fourth tenet, the control of learning is returned to the student so that students determine the timing of their assignments and become acquainted with their own learning style so as to better self-assess their learning. $90.5 \%$ of students agreed that this change had happened in their learner-centered classrooms, and $90.4 \%$ of students believed that being self-directed in their learning was important for them. Students' comments again support that they were positive about this change, although with some trepidation:

- $\quad$ "The learner centered style of class was very different from what I have experienced in other classes. I was not sure how I would like it because so much of the responsibility was on me to make sure that I did everything on time without reminders from professor along the way. But it worked!"

- $\quad$ "I have somewhat mixed feelings about learner-centered teaching. This may partly be due to the ingrained style of learning that I

InSight: A Journal of Scholarly Teaching 
have used for so long. Up until this point, I have almost always had some sort of quiz or test to assess my understanding of information. And I like it when professors provide a lot of structure because that puts me in my comfort zone of knowing exactly what to do. By creating less structured assignments, there was more responsibility on me to figure out what was appropriate. As anxiety-provoking as this initially was, I think that it is a realistic representation of what our jobs and professions will someday be like."

- $\quad$ "Being able to determine when I wanted to turn in assignments as opposed to being told when these assignments were due was an incredible stress reducer... Being encouraged to hand in rough drafts expressed to me that the essay assignments were not about a grade, rather a learning experience."

In understanding the implications of these results, students do seem to initially struggle with the simultaneous freedom and responsibility inherent in a learnercentered model, perhaps mirroring what many first-year college students feel. But if such responsibility is balanced by large measures of support, as is apparent when students feel trusted, they respond well to the challenge.

Weimer's fifth tenet is critical: that assessment measures contribute to student learning and not just towards establishing a grade for individual students. Regarding the extent to which this happened, $100 \%$ of students agreed that assessment measures did contribute to student learning and $95.3 \%$ felt that this change was important to their learning. Again, students' comments were mostly positive in regard to how assessment measures were used, although some students noted some struggles in adapting to a different way of measuring learning:

- "I sometimes viewed the flexible method of homework as a loophole to high accountability (however, I suppose this final selfassessment of learning is holding me accountable!)"

- $\quad$ "The homework assignments changed the way I read. Rather than reading to memorize facts or lists, I thought about bigger questions. Instead of narrowing my focus by reading, I was expanding it. This allowed me to critically think about the articles we read, rather than just memorizing information for a quiz. For me, this fostered a sense of evaluating our reading rather than accepting it...When reading exclusively for a quiz, I tend to remember isolated facts rather than larger concepts from the text. Additionally, the information does not necessarily stay committed to memory for very long."

- $\quad$ "In all honesty, I read the assignments twice when in preparation for my reflection papers, where I would only read once and then re-scan to prepare for quizzes. It seems counterintuitive, but I spent more time reading the assignments after we stopped taking quizzes than I did before."

Somewhat ironically, students worked harder and smarter when less emphasis was placed on grades, pop quizzes, and memorization. These results help abate a fear associated with learner-centered thinking: that students won't learn unless we use giant sticks, in the form of "points", to prod them into working. Instead, they worked even harder when they were working for carrots: specific, timely feedback from the professor and earning greater amounts of trust.

Overall, judging by these students' perceptions, learner-centered teaching does seem to offer some potential as a pedagogical style which helps promote 
critical thinking and assist students in becoming life-long learners. But students did have some concerns about shifting to an entirely learner-centered paradigm, particularly with regard to what happens in the classroom hour itself. Several students suggested that the optimal method to encourage their learning was a blend of traditional teaching and more learner-centered concepts, noting some frustration with class discussions and a desire for some organization and emphasis on key concepts to ensure that they did not get lost:

- "My conclusion about learner-centered teaching is that both teachercentered and learner-centered styles have positives and negatives. I do feel like I 'got' more out of the critical thinking (learner-centered) approach because I had to take control of my learning. Overall, I think I did better with the balance of lecture and discussion that we found towards the middle of the semester."

- "I find it interesting that the freedom of the discussions that was so powerful was also their weakness."

In understanding these and other student comments, it seems that a balance between traditional teaching methods and learner-centered teaching may indeed be the intellectual "sweet spot" for students in that professors retain enough control of the classroom to organize key concepts for students in a meaningful way, even if this means thoughtfully reining in student discussions at times.

\section{Conclusions and Future Directions}

In summarizing the overall findings, graduate students in learning-centered classrooms agreed that their classroom experiences were indeed learner-centered, as described by Weimer (2002). Furthermore, they noted that the paradigm changes they experienced were extremely important in helping them learn. Qualitative data collected, in the form of student quotes, strongly supported the move to a learner-centered paradigm as a positive shift. However, students also note some frustration with not having the skills to flourish in a learner-centered environment, including struggling to participate in focused discussions about the assigned reading and in holding themselves accountable for assignments, although they clearly see the importance of developing these skills. Students also perceive that the professor should retain more control of the classroom experience itself so that critical concepts did not get lost. It may be that a learner-centered attitude, learnercentered relationships, and a learner-centered course design structure (e.g. multiple drafts of papers, formative assessment, low stakes assignments, in-depth homework assignments instead of quizzes/tests) best complements a quasi-learner-centered style in the classroom, in

It may be that a learnercentered attitude, learnercentered relationships, and a learner-centered course design structure best complements a quasilearner-centered style in the classroom, in which the professor retains relatively more power in controlling the learning experiences, discussions, and small group work of students. which the professor retains relatively more power in controlling the learning experiences, discussions, and small group work of students.

Future research is needed to definitively answer some of the questions about learner-centered teaching. Like all work in the field of scholarship of teaching and learning, one must be cautious in generalizing results due to the limited scope of the experiences of a few select classes led by a single teacher. Studies are needed with larger sample sizes and multiple professors across academic subjects to determine if variations exist within these variables. Undergraduate compared to graduate student responses may also differ in terms of their perceptions of learnercentered teaching. Additionally, quasi-experiments in real-world classrooms, which set up two different conditions of learning (one learning-centered and one more traditional) will help answer questions about the impact of learner-centered teaching

InSight: A Journal of Scholarly Teaching 
on students' perceptions of learning, actual content knowledge learned, and the students' depth of thinking about and understanding of the conceptual underpinnings of their chosen field.

\section{References}

Bain, K. (2004). What the best college teachers do. Cambridge, MA: Harvard University Press.

Bilimoria, D. \& Wheeler, J.V. (1995). Learning-centered education: a guide to resources and implementation. Journal of Management Education, 29(3), 402-428.

Blumberg, P. (2007). Problem-based learning: a prototypical example of learning-centered teaching. Journal of Student Centered Learning, 3(2), 111-125.

Brookfield, S. D. (1995). Becoming a critically reflective teacher. San Francisco, CA: Jossey-Bass.

Daley, B. J. (2003). A case for learner-centered teaching and learning. New Directions for Adult and Continuing Education, 98, 2330.

McKeachie, W.J. \& Svinicki, M. (2006). McKeachie's teaching tips. Boston, MA: Houghton Mifflin Company.

Mezekse, B. (2004). Shifting paradigms? Don't forget to tell your students. The Teaching Professor, $18(7), 1$.
Palmer, P. (1998). The courage to teach. San Francisco, CA: JosseyBass.

Ramsey, V. J. \& Fitzgibbons, D.E. (2005). Being in the classroom. Journal of Management Education, 29(2), 333-356.

Robertson, D.R. (2005). Generative paradox in learner-centered college teaching. Innovation Higher Education, 29(3), 181-194.

Steckol, K. F. (2007). Learnercentered teaching in higher education: formative assessment study turns classroom into research lab. The ASHA Leader, 12(5), 14-15.

Thompson, J., Licklider, B., \& Jungst, S. (2003). Learner-centered teaching: Postsecondary strategies that promote "thinking like a professional". Theory into Practice, 42(2), 133-141.

Weimer, M. (2002). Learner-centered teaching: five key changes to practice. San Francisco, CA: JosseyBass.

Wells, M.A. \& Jones, B. D. (2005). Commonsense ISD: an empirical approach to teaching systems analysis and design. Conferences in Research and Practice in Information Technology, 42.

DeDe Wohlfarth is a tenured Associate Professor at Spalding University in the School of Professional Psychology. She has twice won a Kentuckiana Metroversity Award for teaching excellence and has presented at the International Lilly Conference on College Teaching. Her research interests include the scholarship of teaching and learner-centered teaching.

Daniel Sheras, Jess Bennett, Bethany Simon, Jody Pimentel and Laura Gabel are doctoral students in clinical psychology at Spalding University; all are interested in SOTL theory, research, and practice. They are part of a student-teacher collaborative research group collecting qualitative data on learner-centered teaching approaches. 